\title{
Treating pelvic inflammatory disease with doxycycline and metronidazole or penicillin and metronidazole.
}

\author{
P K HEINONEN, ${ }^{*} \mathrm{~K}$ TEISALA, ${ }^{*} \mathrm{R}$ PUNNONEN, ${ }^{*}$ R AINE, $\dagger$ M LEHTINEN, $\ddagger$ A MIETTINEN, $§$ \\ AND J PAAVONEN $\Uparrow$ \\ From the Departments of* Obstetrics and Gynaecology, $\dagger$ Pathology, and $\ddagger$ Medical Microbiology, University \\ Central Hospital, and the Departments of §Biomedical Sciences and $\mid$ Clinical Sciences, University of \\ Tampere, Tampere, Finland
}

SUMMARY The best way of treating pelvic inflammatory disease (PID) is not known. The clinical response to two treatment regimens (penicillin plus metronidazole $v$ doxycycline plus metronidazole) was studied in 33 patients with PID confirmed by laparoscopy and endometrial biopsy. The overall failure rate, according to the criteria used in this study was five of $11(45 \%)$ women with chlamydial PID, none of six women with gonococcal PID, all of four women with chlamydial gonococcal PID, and three $(25 \%)$ of 12 women with non-chlamydial non-gonococcal PID. The failure rate with penicillin plus metronidazole treatment was unacceptably high (53\%), and significantly higher than that with doxycycline plus metronidazole $(19 \%)(p=0.038)$. In most cases the microbiological and histopathological evaluations identified a probable explanation for the poor response to the treatment regimen used.

\section{Introduction}

Acute pelvic inflammatory disease (PID) is usually an ascending polymicrobial infection of the endometrium and fallopian tubes. ${ }^{1-3}$ Though laparoscopy and endometrial sampling have improved its diagnosis, ${ }^{45}$ the microbial aetiology of tubal infection is rarely known. Thus antimicrobial treatment should cover all common causative organisms. ${ }^{6}{ }^{7}$ Previous studies have shown that roughly $15 \%-20 \%$ of patients with acute PID fail to respond to initial treatment, and in up to $30 \%$ the disease recurs. ${ }^{2}$

This study aimed to evaluate the efficacy of two antimicrobial combinations commonly used in the treatment of acute PID.

\section{Patients and methods}

The study group comprised 33 women who had

Address for reprints: Dr P K Heinonen, Department of Obstetrics and Gynaecology, University Central Hospital, SF-33520 Tampere, Finland

Accepted for publication 20 December 1985 laparoscopically diagnosed salpingitis or histopathologically diagnosed endometritis, or both. The presence of salpingitis was assessed using the laparscopic criteria of mild, moderate, or severe salpingitis, ${ }^{8}$ and a single strip endometrial biopsy specimen was obtained, as described. ${ }^{5}$ The histopathological diagnosis of endometritis was based on the presence of plasma cells on endometrial biopsy. Endometritis was classified as mild, moderate, or severe. ${ }^{5}$ Cervical, endometrial, tubal and peritoneal cultures for isolation of Chlamydia trachomatis, Neisseria gonorrhoeae, Mycoplasma hominis, Ureaplasma urealyticum, herpes simplex virus, and anaerobic and facultative bacteria were obtained as described previously. ${ }^{4} \mathrm{We}$ classified all cases according to the culture results for $C$ trachomatis and $N$ gonorrhoeae as follows: chlamydial PID, if $C$ trachomatis but not $N$ gonorrhoeae was isolated from any site: gonococcal PID, if $\boldsymbol{N}$ gonorrhoeae but not $\boldsymbol{C}$ trachomatis was isolated from any site: chlamydial gonococcal PID, if both organisms were isolated; and non-chlamydial non-gonococcal PID, if neither organism was isolated.

Antimicrobial treatment was started intravenously 
immediately after laparoscopy. The patients were unselectively treated either with the combination of penicillin plus metronidazole or doxycycline plus metronidazole. The patients with an even year of birth were given intravenous benzylpenicillin $1.8 \mathrm{~g}$ three times a day plus metronidazole $500 \mathrm{mg}$ three times a day for 48 hours, followed by $660 \mathrm{mg}$ phenoxymethyl penicillin plus $400 \mathrm{mg}$ metronidazole three times a day by mouth to complete 14 days of treatment. The women with an odd year of birth were given intravenous doxycycline hydrochloride $100 \mathrm{mg}$ twice daily plus metronidazole $500 \mathrm{mg}$ three times a day intravenously for 48 hours, followed by $150 \mathrm{mg}$ doxycycline once daily plus metronidazole $400 \mathrm{mg}$ three times per day by mouth to complete 14 days of treatment.

A clinical severity score was derived by grading the presence of cervical motion and uterine and adnexal tenderness on a scale of 0 (absent to normal) to 3 (severe), as described previously. ${ }^{9}$ An intrauterine contraceptive device (IUCD) was present in 14 patients, which was removed before the start of treatment. The clinical examination was repeated 48-72 hours, seven days, and 14 to 16 days after treatment had been started. Cervical cultures for $C$ trachomatis and $N$ gonorrhoeae were repeated at the 14 to 16 days visit. Erythrocyte sedimentation rate, serum C reactive protein concentration, ${ }^{10}$ and white cell count were determined initially. The erythrocyte sedimentation rate and white cell count were repeated after 14 days of treatment.

Treatment failure was defined as follows: no improvement in the clinical severity score during pelvic examination performed 48-72 hours after the start of treatment; presence of pelvic mass, clinical severity score $\geq 5$, positive cervical culture for $N$ gonorrhoeae or $C$ trachomatis, or erythrocyte sedimentation rate higher than half of the initial level at the 14 to 16 days examination.

- Fisher's exact test was used for statistical comparisons.

\section{Results}

Table I shows that the demographic and clinical characteristics of the patient groups were comparable. Seventeen patients were treated with penicillin plus metronidazole, and 16 were treated with doxycycline plus metronidazole.

Table II summarises the response to treatment in 17 patients who received penicillin plus metronidazole. According to our criteria the treatment had failed in nine $(53 \%)$ cases, including three $(75 \%)$ of four patients with chlamydial PID, four (100\%) women with chlamydial gonococcal PID, and two (50\%) of four women with non-chlamydial non-gonococcal PID.
TABLE I Selected characteristics and clinical findings in women treated for acute pelvic inflammatory disease (PID)

\begin{tabular}{|c|c|c|}
\hline Observation & $\begin{array}{l}\text { Penicillin } \\
\text { and } \\
\text { metronidazole }\end{array}$ & $\begin{array}{l}\text { Doxycycline } \\
\text { and } \\
\text { metronidazole }\end{array}$ \\
\hline No of patients & 17 & 16 \\
\hline Age (years)* & $26(9)$ & $23(4)$ \\
\hline Nulliparous & 8 & 8 \\
\hline \multicolumn{3}{|l|}{ Contraception } \\
\hline IUCD & 9 & 5 \\
\hline Hormonal & 2 & 4 \\
\hline Other methods & 4 & 4 \\
\hline None & 2 & 3 \\
\hline History of PID & 3 & 7 \\
\hline Duration of symptoms (days)* & $11(7)$ & $8(8)$ \\
\hline Clinical severity score* & $11(5)$ & $11(5)$ \\
\hline $\begin{array}{l}\text { Erythrocyte sedimentation } \\
\text { rate }(\mathrm{mm} / \mathrm{hour})^{*}\end{array}$ & $34(23)$ & $35(24)$ \\
\hline$C$ reactive protein $(\mathrm{mg} / 1)^{*}$ & $67(54)$ & $53(44)$ \\
\hline
\end{tabular}

* Values are mean (SD).

TABLE II Occurrence of treatment failures in relation to isolation of Chlamydia trachomatis or Neisseria gonorrhoeae in 33 patients treated for acute pelvic inflammatory disease (PID)

\begin{tabular}{lll}
\hline & \multicolumn{2}{l}{ No of failures/No treated with: } \\
\cline { 2 - 3 } & $\begin{array}{l}\text { Penicillin } \\
\text { and } \\
\text { metronidazole }\end{array}$ & $\begin{array}{l}\text { Doxycycline } \\
\text { and } \\
\text { metronidazole }\end{array}$ \\
\hline Chlamydial & $3 / 4$ & $2 / 7$ \\
Gonococcal & $0 / 5$ & $0 / 1$ \\
Chlamydial gonococcal & $4 / 4$ & $0 / 0$ \\
Non-chlamydial non-gonococcal & $2 / 4$ & $1 / 8$ \\
Total (\%) & $9 / 17(53)$ & $3 / 16(19)$ \\
\hline
\end{tabular}

Table III shows the microbiological findings and severity of endometritis and salpingitis in patients treated with penicillin plus metronidazole. Of eight women who had PID associated with $C$ trachomatis infection, seven (88\%) failed to respond to penicillin plus metronidazole treatment (tables II and III). In both patients with non-chlamydial non-gonococcal PID in whom treatment failed Escherichia coli, or Haemophilus influenzae, was isolated from the fallopian tubes (table III). In one case $\boldsymbol{H}$ influenzae was isolated from tubal aspirate, and in the other $E$ coli was isolated from the tube and the endometrium. In one patient (case 7) who responded clinically $E$ coli was isolated from the fallopian tube. Anaerobic bacteria were isolated from the endometrium in seven cases. Patients who had not responded to penicillin plus 
Treating pelvic inflammatory disease with doxycycline or penicillin (both with metronidazole)

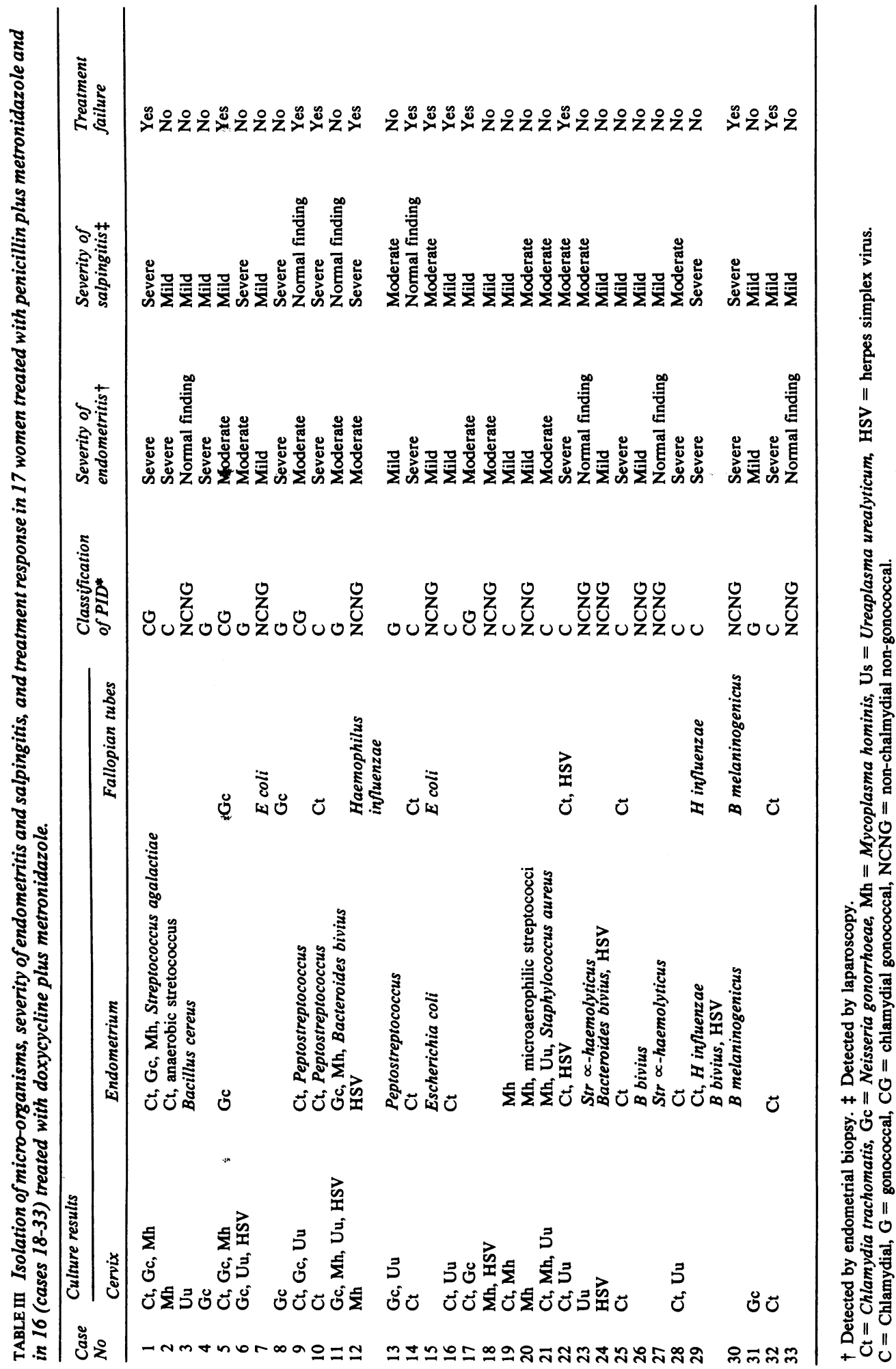


metronidazole were subsequently treated with doxycycline (three cases), or with the combination of sulphadiazine plus trimethoprim (four cases), or with amoxycillin (two cases).

Table III summarises the findings and clinical response in the 16 patients who were treated with doxycycline plus metronidazole. This treatment regimen failed in three (19\%) patients, including two of seven $(29 \%)$ with chlamydial PID and one of eight (12\%) patients with non-chlamydial non-gonococcal PID (tables II and III). Bacteroides melaninogenicus was isolated from the fallopian tubes in the patient with non-chlamydial non-gonococcal PID who failed to respond. She developed pelvic peritonitis with a tubal abscess, which was aspirated three times. Actinomyces israelii was isolated from the removed IUCD.

The severity of endometritis seemed to predict treatment failure slightly better than the severity of salpingitis. Thus treatment failure occurred in six of 12 women $(50 \%)$ with severe endometritis, and three of seven women (43\%) with severe salpingitis (table III).

\section{Discussion}

Optimal treatment for PID is difficult to determine for the following reasons: the microbial aetiology of tubal infection is rarely known; a uniform objective clinical scoring system to evaluate the short term response to treatment has not been widely used; and long term follow up studies for tubal infertility after antimicrobial treatment are extremely difficult. In this study we used the clinical scoring system for tenderness developed by McCormack et al ${ }^{9}$ to assess the clinical response to antimicrobial treatment. We also used laparoscopy, endometrial biopsy, and microbiological sampling of the cervix, endometrium, tubes, and peritoneal cavity to obtain objective evidence of the presence, severity, and aetiology of PID.

Both single drug and combination drug treatments have been used in the treatment of acute PID. Failure rates of previous treatment trials have ranged from 0\%-55\% (mean 12\%). ${ }^{11}{ }^{12}$ The failure rate for the combination of penicillin plus metronidazole in this study was unacceptably high (53\%). This is undoubtedly due to the fact that penicillin or metronidazole are not effective against $\boldsymbol{C}$ trachomatis. Our findings agree with those of previous studies on women with cervicitis. ${ }^{13}$

Doxycycline plus metronidazole has been recommended for the treatment of acute PID by the Centers for Disease Control, United States of America. ${ }^{14}$ This combination is effective against both anaerobes and $C$ trachomatis. In this trial the failure rate was $19 \%$, which is significantly $(p=0.038)$ lower than that for penicillin plus metronidazole (53\%). Our results agree with those of previous studies. ${ }^{15-20}$ In two of three cases with no response to doxycycline plus metronidazole $C$ trachomatis was isolated from the cervix, endometrium, and fallopian tubes. Severe plasma cell endometritis was detected by endometrial biopsy. The dose, or the duration of the treatment, may have been insufficient. Resistance to doxycycline among $C$ trachomatis strains has not been described.

Histopathological examination showed severe endometritis in 12 patients, and in eight of these $C$ trachomatis was also isolated from the endometrium. Remarkably, severe endometritis was detected in $50 \%$ of the patients who failed to respond to the antimicrobial treatment. This finding deserves further study. Perhaps the presence of severe endometritis predicts the failure of conventional treatment. In such cases, therefore, the treatment should be more effective with higher doses and longer duration. Serial determinations of serum $\mathrm{C}$ reactive protein might also be helpful in monitoring response to the treatment.

As previous studies have shown a high rate of anaerobic bacteria in the peritoneal fluid, or endometrial cavity, of women with PID, we combined metronidazole with both the antimicrobial agents used to gain better coverage against anaerobic bacteria. In such studies, however, the specimens were obtained by culdocentesis, or transcervically, so that vaginal contamination of the specimens might have occurred. ${ }^{31521}$ In this study we found a much lower prevalence of anaerobic bacteria in the endometrial and tubal specimens. The use of metronidazole is probably unnecessary in the treatment of uncomplicated PID without pelvic abscesses. On the other hand, in this study mixed facultative and anaerobic bacteria were commonly found in the endometrial specimens, supporting the argurient for using metronidazole in the combination treatment, though the possibility of cervicovaginal contamination is extremely difficult to rule out when any transcervical sampling method is used.

$E$ coli, $H$ influenzae, and $B$ melaninogenicus were examples of non-gonococcal and non-chlamydial organisms isolated directly from the fallopian tubes. Three such cases did not respond to the initial treatment. These findings stress the importance of obtaining microbiological specimens directly from the inflamed tubes. Laparoscopy is necessary to obtain these specimens and to evaluate the severity of the disease. In two cases $H$ influenzae was isolated from tubo-ovarian abscesses when these abscesses were aspirated under laparoscopic control. In addition to appropriate antimicrobial treatment and laparoscopic damage of abscess, further surgical interventions were not required in any of the cases. 
In conclusion, our study clearly shows that penicillin plus metronidazole is an inadequate treatment for acute PID. Doxycycline plus metronidazole treatment showed a significantly lower (19\%) clinical failure rate. We were able to identify a reasonable microbiological or histopathological explanation for the poor response in most cases of treatment failure. This emphasises the importance of extensively evaluating patients with suspected PID.

This study was supported by grant number $7939 / 304 / 83$ from the Academy of Finland.

\section{References}

1. Jacobson L, Weström L. Objectivized diagnosis of acute pelvic inflammatory disease. Diagnostic and prognostic value of routine laparoscopy. Am J Obstet Gynecol 1969;105:1088-98.

2. Weström L. Incidence, prevalence, and trends of acute pelvic inflammatory disease and its consequences in industrialized countries. Am J Obstet Gynecol 1980;138:880-92.

3. Sweet RL. Diagnosis and treatment of pelvic inflammatory disease in the emergency room. Sex Transm Dis 1981;8:156-63.

4. Heinonen PK, Teisala K, Punnonen R, Miettinen A, Lehtinen $\mathrm{M}$, Paavonen J. Anatomic sites of upper genital tract infection. Obstet Gynecol 1985;66:384-90.

5. Paavonen J, Aine R, Teisala K, et al. Chlamydial endometritis. $J$ Clin Pathol 1985;38:726-32.

6. Bell TA, James JF. Computer-assisted analysis of the therapy of acute salpingitis. Am J Obstet Gynecol 1980;138:1048-54.

7. Thompson SE III, Hager WD, Wong KH, et al. The microbiology and therapy of acute pelvic inflammatory disease in hospitalized patients. Am J Obstet Gynecol 1980;136:179-86.

8. Hager WD, Eschenbach DA, Spence MR, Sweet RL. Criteria for diagnosis and grading of salpingitis. Obstet Gynecol 1983;61:113-4.

9. McCormack WM, Nowroozi K, Alpert S, et al. Acute pelvic inflammatory disease. Characteristics of patients with gonococcal and nongonococcal infection and evaluation of their response to treatment with aqueous procaine penicillin $\mathbf{G}$ and spectinomycin hydrochloride. Sex Transm Dis 1977;4:125-31.

10. Harmoinen A, Perko M, Grönroos P. Rapid quantitative determination of C-reactive protein using LKB 8600 reaction rate analyzer. Clin Chim Acta 1981;111:117-20.

11. Rees E. The treatment of pelvic inflammatory disease. $A m J$ Obstet Gynecol 1980;138:1042-7.

12. Brunham RC. Therapy for acute pelvic inflammatory disease: a critique of recent treatment trials. Am J Obstet Gynecol 1984;148:235-40.

13. Stamm WE, Guinan ME, Johnson C, Starcher T, Holmes KK, McCormack WM. Effect of treatment regimens for Neisseria gonorrhoeae on simultaneous infection with Chlamydia trachomatis. N Engl J Med 1984;310:545-9.

14. Centers for Disease Control. Sexually transmitted diseases treatment guidelines 1982. MMWR 1982;31:43-62.

15. Monif GRG. Significance of polymicrobial bacterial superinfection in the therapy of gonococcal endometritis-salpingitisperitonitis. Obstet Gynecol 1980;55(suppl 5):154-161.

16. Andersson PO, Hackl H, Jensen P, Larsen KR. A comparison of two different dosages of pivampicillin and doxycycline in patients with gynaecological infections. Curr Med Res Opin 1980;6:513-7.

17. Gjønnaess H, Dalaker K, Urnes A, et al. Treatment of pelvic inflammatory disease effects of lymecycline and clindamycine. Current Therapeutic Research 1981;29:885-92.

18. Monif GRG, Welkos SL, Baer H. Clinical response of patients with gonococcal endocervicitis and endometritis-salpingitisperitonitis to doxycycline. Am J Obstet Gynecol 1977;129:614 22.

19. Spence MR, Genadry R, Raffel L. Randomized prospective comparison of ampicillin and doxycycline in the treatment of acute pelvic inflammatory disease in hospitalised patients. Sex Transm Dis 1981;8:164-6.

20. Monif GRG. Clinical staging of acute bacterial salpingitis and its therapeutic ramifications. Am J Obstet Gynecol 1982;143:489-95.

21. Eschenbach DA, Buchanan T, Pollock HM, et al. Polymicrobial etiology of acute pelvic inflammatory disease. $N$ Engl J Med 1975:293:166-71 